\title{
EFEITOS ANTROPICOS E SAZONAIS NA QUALIDADE DA ÁGUA DO RIO DO CARMO
}

\author{
A. G. SILVA' e L. D. SOUZA ${ }^{2}$ \\ ${ }^{1}$ Mestrando em Ciências Naturais, Técnico de Laboratório - Instituto Federal do RN - Campus Pau dos Ferros \\ ${ }^{2}$ Laboratório de Ciências Ambientais e Materiais - LACAM - Universidade do Estado do Rio Grande do Norte \\ E-mail: alriberto.silva@ifrn.edu.br - luizuern@bol.com.br
}

Artigo submetido em dezembro/2012 e aceito em novembro/2013

\section{RESUMO}

Mesmo estando um pouco distante dos grandes centros urbanos, o Rio do Carmo, localizado na região Oeste do estado do Rio Grande do Norte, sofre os impactos das ações humanas. Ao longo do seu curso são desenvolvidas diversas atividades como aqüicultura, salineira, petrolífera e agricultura, como o cultivo do melão, além da existência de algumas cidades e povoados. Diante do exposto, torna-se evidente a importância de investigar quais os impactos que estas fontes antrópicas geram na qualidade da água do Rio do Carmo. Este trabalho teve como objetivo investigar a influência antrópica nas propriedades físicas, químicas e microbiológicas (propriedades limnológicos) da água deste rio. Para tal, foram coletadas amostras de água em quatro pontos do Rio do Carmo, localizados no seu curso a partir da sua parte perenizada, ou seja, da barragem de Umarí. Em todos os pontos foram determinadas as propriedades necessárias para o cálculo dos índices de qualidade da água (IQA). Os resultados indicam que a qualidade da água ainda é boa no trecho analisado, mas a mesma diminui no percurso na direção da foz e já apresenta alguns parâmetros como à presença de coliformes, oxigênio dissolvido e DBO com valores altos e fora dos padrões recomendados nos pontos próximos a cidade de Upanema e das atividades agropastoris. Com intensidades variadas os valores dos parâmetros individuas e dos IQAs, são fortemente influenciados pela espacialidade e pela sazonalidade típica da região. Desta forma, constata-se a necessidade de ações e projetos que visem mitigar as atividades que estão poluindo o Rio do Carmo, principalmente próximo à cidade de Upanema e nas regiões em torno das atividades de fruticultura irrigada intensiva.

PALAVRAS-CHAVE: Rio do Carmo, qualidade da água, sazonalidade e antropicidade.

\section{SEASONAL AND ANTHROPOGENIC EFFECTS ON THE WATER QUALITY OF RIVER CARMO}

\section{ABSTRACT}

Even being a little distant from large urban centers, the Carmo River, located in the western region of the state of Rio Grande do Norte, is not immune to the impacts of human actions. Along its course are developed several activities such as aquaculture, Salineira, oil and agriculture, as the cultivation of melons besides the existence of some cities and many villages. Given the above, it is evident the importance of investigating the impacts that these anthropogenic sources generate the water quality of the Rio do Carmo. This study aimed to investigate the anthropogenic influence on the physical, chemical and microbiological characteristics of water and sediment of the river. To this end, we collected samples of water and sediments at four points in the Carmo River located in its course from its part with constant flow, in other words since dam Umarí. At all points were determined the properties necessary for calculating the water (IQA). The results indicate that water quality is still good in the stretch analyzed, but decreases in the same way towards the mouth and already includes some parameters such as the presence of coliform, dissolved oxygen and BOD, with high and outside the recommended standards in sections near the city of Upanema and agropastoral activities. With varying intensity parameter values are single and SEQI, are strongly influenced by the spatiality and the seasonality typical of the region. Thus, there is a need for actions and projects aimed at alleviating the activities that are polluting the Rio do Carmo, particularly near the city of Upanema and regions around the activities of intensive irrigated horticulture.

KEYWORDS: Carmo River, Water quality, Seasonality and Anthropogenic 


\section{EFEITOS ANTROPICOS E SAZONAIS NA QUALIDADE DA ÁGUA DO RIO DO CARMO}

\section{INTRODUÇÃO}

A água constitui-se um elemento indispensável à sobrevivência de todos os organismos vivos, além disso, é extremamente importante para a manutenção do clima na Terra. (TUNDISI, 2003 apud SIQUEIRA et al., 2012). Outro ponto importante, diz respeito a sua disponibilidade no planeta. É comum a terra ser chamada muitas vezes de planeta água ou azul. Essas denominações apenas enfatizam uma afirmação sobre a constituição da superfície terrestre, que segundo Miller (2008), é de aproximadamente $71 \%$ de água. Esta afirmativa, a princípio até serve de consolo para a população mundial que cresce, a cada dia e convive diariamente com a instabilidade de abastecimento de água potável. Porém deste percentual só $8,0 \times 10^{-7} \%$ está acessível aos seres humanos através de recursos superficiais. Ainda se tratando quantidade, bem como da qualidade, d'água superficial disponível (quando comparado ao total de $71 \%$ ) torna-se ainda menor quando o assunto é sua potabilidade. Para Tundisi, 2003 apud Siqueira et al., 2012, a água pode apresentar qualidades variáveis, dependendo do local e das condições de sua origem. O suprimento de água doce de boa qualidade é essencial para o desenvolvimento econômico, para a qualidade de vida das populações humanas e para a sustentabilidade dos ciclos dos nutrientes no planeta.

As águas superficiais são, constantemente, renovadas e purificadas através de seu ciclo hidrológico, bem como do seu movimento, dinâmico, nos rios e lagos, que acabam diluindo e dispersando poluentes e contaminantes. Entretanto, este autopoder depurante está cada vez mais ameaçado em virtude da grande quantidade de carga poluidora que é lançada diariamente nesses ecossistemas, principalmente, de atividades agropecuárias intensivas, mineração, humanas e industriais. Dentre estas fontes as atividades agropecuárias e os efluentes urbanos e industriais podem ser destacados como os principais responsáveis pelo decréscimo da qualidade das águas superficiais. Juntos provocam um efeito deletério, através do desmatamento das matas ciliares; assoreamento dos rios; aumento de turbidez; aumento da concentração de nutrientes, organismos patogênicos, metais e agroquímicos; alteração do equilíbrio iônico d'água e incremento no consumo de oxigênio dissolvido (ARAUJO et al., 2007; LOPES, 2007; MERTEN et al., 2002; RODRIGUES, 2006).

Uma forma eficiente e importante de investigar a influência antrópica nos recursos hídricos superficiais é utilizando-se dos programas de monitoramento ambiental. Estes programas são ferramentas utilizadas para conhecer a qualidade da água, em função do estudo dos parâmetros limnológicos da água. Outro mecanismo muito utilizado como ferramenta de informação sobre qualidade d'água são os índices de qualidade da água (IQAs). Os IQAs são a junção de 9 indicadores individuais pré-estabelecidos de qualidade da água em um número adimensional que varia de 0 a 100. Com base nessas informações é possível propor ações mitigadoras de controle da poluição, de gerenciamento ambiental, de informação a sociedade civil e aos dirigentes políticos. Segundo Guazzelli (1999) apud Ferreira; Ide (2001), um IQA pode ser utilizado para diversos fins como, por exemplo, informar sobre a qualidade da água ao público e aos executivos da alta administração; acompanhar a qualidade dos recursos hídricos superficiais; identificar problemas de qualidade da água, que demandem estudos especiais em trechos de rios; avaliar o desempenho de programas de controle da poluição e servir de instrumentos para a gestão dos recursos hídricos. 


\section{Caracterizando a área de estudo}

Localizada na região oeste do estado do Rio Grande do Norte, a Bacia Hidrográfica do Rio do Carmo (BHRC) é o principal afluente da bacia hidrográfica do Rio Apodi/Mossoró. Nela encontra-se construídos reservatórios importantes, com destaque para a barragem Jessé Pinto Freire (barragem Umarí), terceira maior do estado em capacidade de reserva d'água (aproximadamente 292 milhões de $\mathrm{m}^{3}$ ), que torna o Rio do Carmo (principal curso d'água) perene a sua jusante, conforme ilustrado na Figura 1 (SECRETÁRIA ESTADUAL DE MEIO AMBIENTE E RECURSOS HÍDRICOS-SEMARH, 2012).

Segundo a classificação de Thornthwaite e Mather (1955) apud SERHID (2007), esta bacia possui clima semiárido com grande deficiência hídrica de julho a dezembro, megatérmico, apresentando pequena variação da evapotranspiração potencial, ao longo do ano (DdA'a'). Os principais parâmetros climatológicos anuais estão listados na Tabela 1 (SECRETARIA DE ESTADO DOS RECURSOS HÍDRICOS - SERHID, 2007). Tem como período de maior precipitação pluviométrico o trimestre de fevereiro a maio, com precipitações que correspondem a $64 \%$ do total anual. Outro ponto importante sobre a pluviometria da bacia, diz respeito à tendência de decréscimo da precipitação anual de montante para jusante no curso principal do Rio do Carmo (SERHID, 2005).

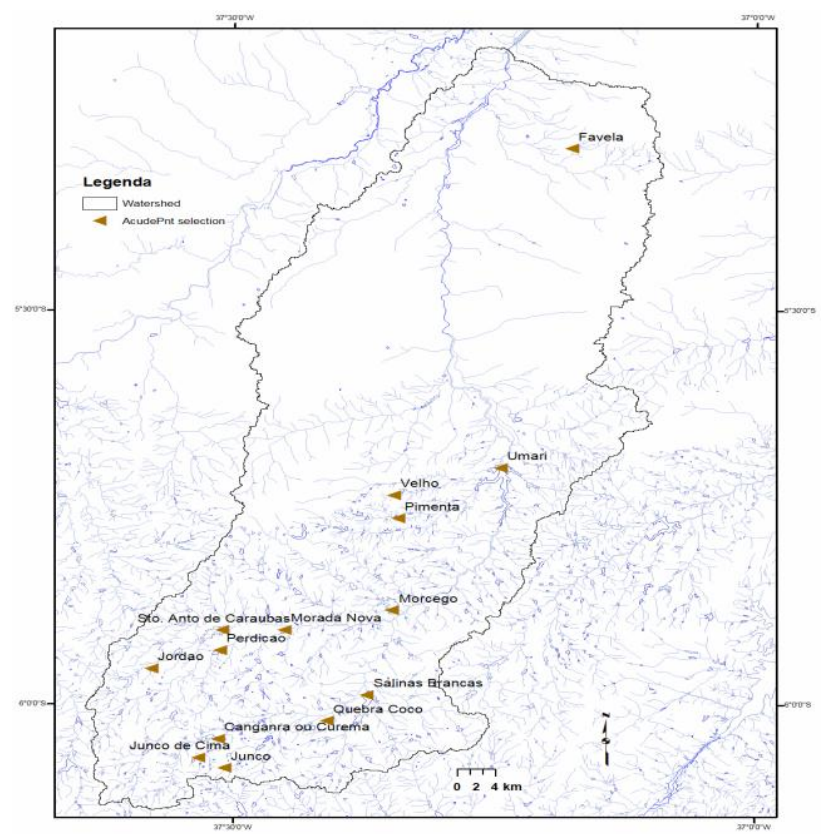

Figura 1- Bacia hidrográfica do Rio do Carmo

Tabela 1 - Principais parâmetros climatológicos do Rio do Carmo

\begin{tabular}{ll}
\hline PARÂMENTRO & RESULTADO \\
\hline Pluviometria total média anual & $765,8 \mathrm{~mm}$ \\
\hline Evaporação média anual & $2.658,6 \mathrm{~mm}$ \\
\hline Evapotranspiração potencial média anual & $1.777,2 \mathrm{~mm}$ \\
\hline Insolação total média anual & $2.780,1 \mathrm{horas}$ \\
\hline Umidade relativa média anual & $68,5 \%$ \\
\hline Temperatura média anual: média das máximas & $33,4^{\circ} \mathrm{C}$ \\
\hline Temperatura média anual: média das médias. & $27,2^{\circ} \mathrm{C}$ \\
\hline Temperatura média anual: média das mínimas & $22,7^{\circ} \mathrm{C}$ \\
\hline Fonte - SERHID (2007).
\end{tabular}


A Assim como em boa parte do Brasil, onde as informações sobre a qualidade d'água são incipientes ou inexistentes, com a BHRC esta realidade não é diferente. Ela encontra-se inserida quase que completamente na Bacia Potiguar, sobre solos de formação Jandaíra e Açu. Com exceção do alto curso do rio, onde pode-se encontrar caatinga arbórea, a bacia BHRC possui uma vegetação predominantemente constituída de caatinga arbustiva com tendência ao crescimento antrópico (áreas de agricultura e desmatamento em geral) no sentido sul-norte (SERHID, 2005; ANGELIM et al., 2007).

Assim como nas demais bacias e micro-bacias que fazem parte da rede hidrológica do estado, onde é marcante a presença antrópica, a BHRC tem passado e vem passando problemas vinculados à poluição de suas águas, desmatamento da mata ciliar e assoreamento do rio (SERHID, 2005; OLIVEIRA, 2001). A origem destes problemas está ligada às fontes pontuais e difusas de poluição como cidades (Upanema) e comunidades (Suçuarana, Sítio Carmo, Melancias e Poço Verde), agricultura de subsistência e intensiva (fruticultura irrigada, com destaque para a cultura do melão), exploração de petróleo, aquicultura (piscicultura e carcinicultura) e atividade salineira em sua região estuarina (SERHID, 2005). Apesar do conhecimento do risco de degradação da qualidade d'água a que esta sujeita ás águas da BHRC, poucos são os trabalhos realizados e publicados sobre o estado em que se encontra à qualidade de suas águas (OLIVEIRA, 2001; RIO GRANDE DO NORTE, 2011).

Sabe-se que um grande problema ambiental que BHRC esta enfrentando, em especial o trecho inferior do Rio do Carmo, diz respeito a elevada concentração de sal, no solo e na água, advindos das atividades salineiras. Impacto este, decorrente da elevada concentração de indústrias salineiras na sua foz, próximo do encontro com o Rio Mossoró, sendo registrado um grande desastre ecológico em seu currículo. Em 1997, um tanque da empresa CIMSAL se rompeu e liberou um grande volume de águas-mães, que foram empurradas para dentro do lagamar do rio pela maré alta (SERHID, 2007). Outro problema que provavelmente a BHRC esta enfrentando e que vem passando despercebido pela população e pelos órgãos de controle e fiscalização ambiental, são os passivos ambientais advindos da agricultura, em especial a fruticultura irrigada do melão que é desenvolvida com as águas do Rio do Carmo. Em toda região em que está sendo praticada, a agricultura intensiva causa poluição e contaminação dos recursos hídricos superficiais e subterrâneos em função do uso de agroquímicos e perda de biodiversidade vegetal e animal em função desta poluição.

Com base nestas informações e considerando a importância ambiental e econômica da BHRC para a região, este trabalho teve como objetivo avaliar os impactos das atividades humanas na qualidade da água do Rio do Carmo, em seu trecho médio (da barragem de Umarí até a cidade de Mossoró), usando o índice de qualidade da água (IQA) e considerando o efeito da sazonalidade no resultado.

\section{MATERIAS E METODOS}

\section{Pontos e Coletas}

Os pontos de coleta (Figura 2) foram estrategicamente escolhidos para fornecerem um ponto que fosse considerado como padrão, e três pontos que permitissem verificar a influência da cidade de Upanema e de uma plantação industrial de melão na qualidade da água. Eles foram georreferenciados ao longo do curso Rio do Carmo utilizando um GPS com as coordenados geográficas adquiridas em UTM, conforme mostrado na Tabela 2. 
Avaliou-se a qualidade da água do Rio do Carmo usando o IQA, observando o efeito sazonal sobre o mesmo, bem como, do efeito dos períodos chuvoso e seco nos indicadores individuais de qualidade da água. Para tanto, foram realizadas duas coletas. A primeira ocorreu no dia 23 de novembro de 2011 (período seco) e a outra no dia 26 de maio de 2012 (período chuvoso).

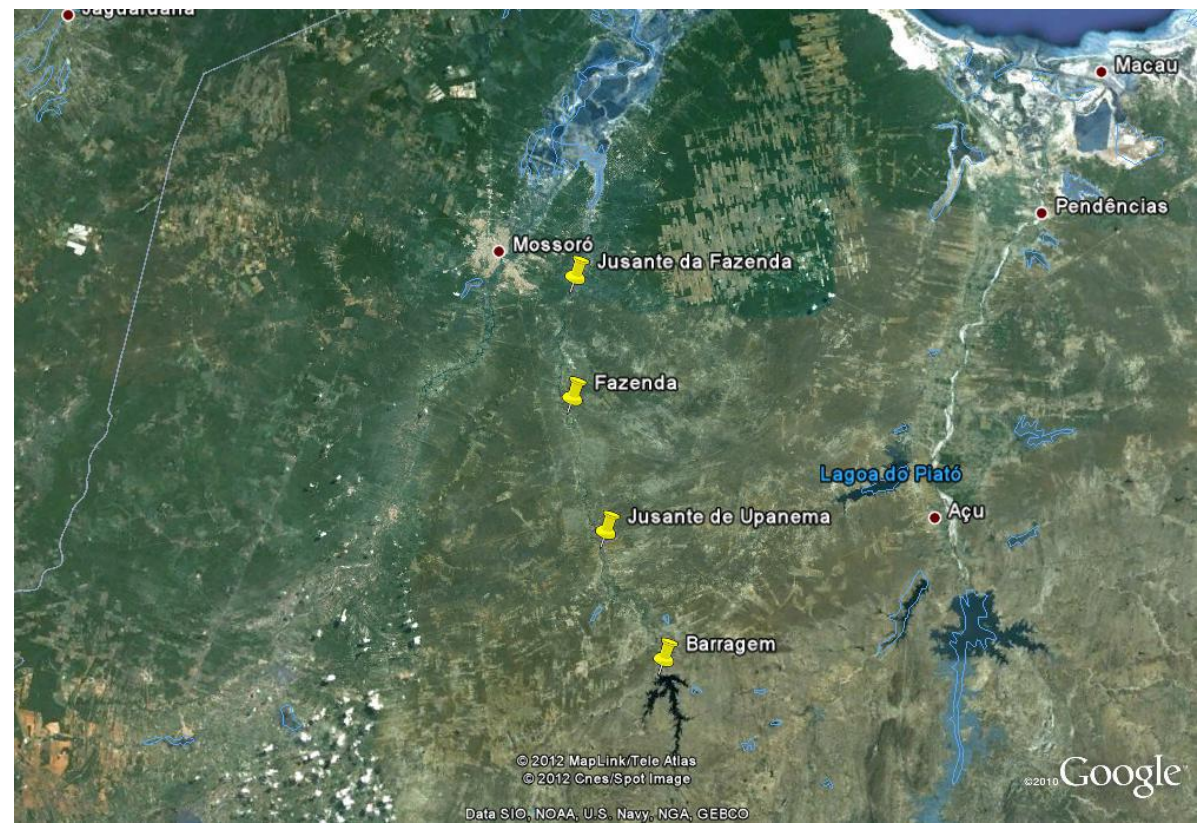

Figura 2 - Localização geográfica dos pontos de coleta

Tabela 2 - Localização dos pontos de coleta, suas coordenadas geográficas em UTM e função do ponto no estudo.

\begin{tabular}{|c|c|c|c|}
\hline \multirow{2}{*}{ PONTO } & \multicolumn{2}{|c|}{ COORDENADAS (UTM) } & \multirow{2}{*}{ FUNÇÃO } \\
\hline & LESTE & NORTE & \\
\hline $\begin{array}{l}\text { Montante Barragem } \\
\text { (MB) }\end{array}$ & 693.554 & 9.770 .174 & $\begin{array}{l}\text { Padrão de comparação para as modificações detectadas } \\
\text { na qualidade da água. }\end{array}$ \\
\hline $\begin{array}{l}\text { Jusante de Upanema } \\
\text { (JU) }\end{array}$ & 689.301 & 9.387 .253 & $\begin{array}{l}\text { Avaliar o efeito da cidade de Upanema nos resultados por } \\
\text { comparação da modificação causada nos resultados do } \\
\text { ponto padrão. }\end{array}$ \\
\hline $\begin{array}{l}\text { Na área da fazenda } \\
(\mathrm{AF}) \text {. }\end{array}$ & 687.827 & 9.407 .006 & $\begin{array}{l}\text { Ver a influencia da fazenda por comparação da } \\
\text { modificação causada no ponto anterior, neste ponto e no } \\
\text { próximo ponto. }\end{array}$ \\
\hline $\begin{array}{l}\text { Jusante da fazenda } \\
\text { (JF). }\end{array}$ & 691.499 & 9.419 .539 & $\begin{array}{l}\text { Servir de base para verificar a influencia da fazenda de } \\
\text { melão. }\end{array}$ \\
\hline
\end{tabular}

\section{Coletas}

Realizaram-se as duas coletas conforme orientações prescritas na NBR 9897(ABNT, 1987) (Planejamento de amostragem de efluentes líquidos e corpos receptores), NBR 9898(ABNT, 1987) (Preservação e técnicas de amostragem de efluentes líquidos e corpos receptores) e no Standard Methods for Examination of Water and Wastewater (APHA). Para tanto, formulou-se a ficha de coleta e uma tabela com as observações a serem seguidas de acordo com cada parâmetro que seria analisado (Tabela 3). 
Tabela 3 - Parâmetros, coletores, condições de preservação e tempos de armazenamentos usados para coleta e analise das amostras.

\begin{tabular}{|c|c|c|c|}
\hline INDICADOR & RECIPIENTE & PRESERVAÇÃO & $\begin{array}{c}\text { TEMPO DE } \\
\text { ARMAZENAMENTO } \\
\end{array}$ \\
\hline $\begin{array}{l}\text { Oxigênio dissolvido, } \mathrm{pH} \\
\text { e temperatura }\end{array}$ & $\begin{array}{l}\text { Medido } \\
\text { In situ }\end{array}$ & $\begin{array}{l}\text { Medido } \\
\text { In situ }\end{array}$ & $\begin{array}{c}\text { Medido } \\
\text { In situ } \\
\end{array}$ \\
\hline Coliformes fecais & $\begin{array}{l}\text { Vidro, Plástico. } \\
\text { Esterilizado à } 105 \text { ㄷ; } 1 \\
\text { atm, durante uma hora. }\end{array}$ & Refrigerar a 4Co & 24 horas \\
\hline DBO & Vidro, Plástico & Refrigerar a 4Co & 6 horas \\
\hline Nitrogênio total & Vidro, Plástico & $\begin{array}{c}\mathrm{H}_{2} \mathrm{SO}_{4} \text { conc. até } \mathrm{pH}<2 . \\
\text { Refrigerar a } 4^{\circ} \mathrm{C}\end{array}$ & 28 dias \\
\hline Turbidez & Vidro, Plástico & $\begin{array}{c}\text { Refrigerar 4ㅇ } \mathrm{C} \text { e manter ao } \\
\text { abrigo da luz }\end{array}$ & 24 horas \\
\hline Sólidos Totais & Vidro, plástico & Refrigerar $4 \stackrel{\circ}{ } \mathrm{C}$ & 7 dias \\
\hline Nitrato & Vidro & $\begin{array}{c}\mathrm{H}_{2} \mathrm{SO}_{4} \text { conc. até } \mathrm{pH}<2 \mathrm{e} \\
\text { Refrigeração 4ㅇ C }\end{array}$ & 28 dias \\
\hline
\end{tabular}

\section{Metodologias de análises}

Com exceção do OD, pH e a temperatura que foram medidos em campo utilizando-se medidor multiparamétrico portátil Orion* 5-Star da Thermo Scientific, os demais parâmetros (CF. DBO, NT, Tur. NT e ST) foram quantificados utilizando-se das estruturas dos laboratórios de Biologia I, de Eletroquímica e Química Analítica (LEQA) e do Laboratório de Catálise, Ambiente e Materiais (LACAM), todos pertencentes a Universidade do Estado do Rio Grande do Norte-UERN. Todas as análises seguiram as orientações prescritas pelo Standard Methods for Examination of Water and Wastewater (APHA).

\section{Índice de Qualidade da Água - IQA}

Em 1970, com financiamento da National Sanitation Foundation, Brown, McClelland, Deininger e Tozer apresentaram o mais conhecido índice de qualidade da água. O mesmo se baseia nos paramentos oxigênio dissolvido (OD), potencial hidrogeniônico $(\mathrm{pH})$, temperatura $(\mathrm{T})$, turbidez (Tur), sólidos totais (ST), nitrogênio-nitrato $\left(\mathrm{N}-\mathrm{NO}_{3}\right)$, fósforo total (PT), coliformes Fecais (CF) e demanda bioquímica de oxigênio a $20 \cong \mathrm{C}$ e durante 5 dias de incubação $\left(\mathrm{DBO}_{5,20} \mathrm{\circ}\right.$ ) para 0 cálculo do índice (DERISIO, 2007). Além disso, a cada parâmetro foi atribuído um número (0 - 1$)$ que corresponde sua importância em termos de indicador de qualidade d'água e um número (0100) que corresponde a qualidade individual do parâmetro.

No Brasil, no que diz respeito a índice de qualidade da água, destaca-se o IQA adaptado pela Companhia Ambiental do Estado de São Paulo (CETESB) a partir do IQA-NSF. Para o IQA da CETESB a variável $\mathrm{N}-\mathrm{NO}_{3}$ é substituída pelo nitrogênio total (NT), devido à presença de outras formas de nitrogênio (orgânico e amoniacal) nas águas. Mas caso a concentração de $\mathrm{N}-\mathrm{NO}_{3}$ seja à forma predominante em um rio é possível aplicar a curva de NT sem problemas (SÃO PAULO, 2008; COSTA, 2008; AGÊNCIA ESTADUAL DE MEIO AMBIENTE - CPRH, 2006 2007).

Para efetuar o cálculo do IQA (SÃO PAULO, 2008) realiza-se o produtório dos noves parâmetros que compõe o índice. Para tal, utiliza-se a equação 1:

$$
\text { IQA }=\prod_{\mathbf{i}=\mathbf{1}}^{\mathbf{n}} \mathbf{q}_{\mathrm{i}}{ }^{\mathrm{wi}}
$$


onde:

IQA: Índice de Qualidade das Águas, um número entre 0 e 100;

qi: qualidade do i-ésimo parâmetro, um número entre 0 e 100, obtido da respectiva "curva média de variação de qualidade desse parâmetro", em função de sua concentração ou medida;

wi: peso correspondente ao i-ésimo parâmetro, um número entre 0 e 1, atribuído em função da sua importância para o cálculo global de qualidade.

De acordo com o resultado do produtório a água é classificada segundo a Tabela 4.

Tabela 4 - Qualidade da água de acordo com o valor do IQA

\begin{tabular}{cc}
\hline Qualidade d'água & Faixa do IQA \\
\hline Ótima & $80-100$ \\
\hline Boa & $52-79$ \\
\hline Regular & $37-51$ \\
\hline Ruim & $20-36$ \\
\hline Péssima & $0-19$ \\
\hline
\end{tabular}

Fonte: SÃO PAULO (2008).

\section{RESULTADOS E DISCUSSÕES}

De acordo com a resolução CONAMA no 357/2005, que dispõe sobre a classificação dos corpos de água e diretrizes ambientais para o seu enquadramento, os recursos hídricos superficiais são classificadas em águas doces (salinidade $\leq 0,5 \%$ ), salobras $(0,5 \%$ < salinidade $<$ $30 \%$ ) e salgadas ( $30 \%$ o salinidade). Elas são também classificados em treze classes conforme os usos e destinos da água. Assim, de acordo com esta resolução e das informações obtidas em campo, sobre cada ponto, os quatro pontos monitorados neste trabalho podem ser enquadrados como águas doces tipo III. A definição da classe de enquadramento das águas é condição preponderante para se estabelecer, ao longo da discussão, os limites permissíveis de cada parâmetro ambiental analisado (SIQUEIRA, 2012).

Além disso, deve-se ter em mente que os parâmetros limnológicos de rios é fortemente influenciado pelas águas pluviais, uma vez que, as mesmas são responsáveis pela lixiviação, percolação e carreamento de componentes para esses ecossistemas. Sendo assim, a estação chuvosa tem o efeito sazonal de alterar os parâmetros estudados e os índices calculados de acordo com o material que elas carreiam para o leito do rio (MARAIS et al, 2010). Sabendo que para esta região o período com maior incidência de chuva, está compreendido entre os meses de janeiro a junho e que o período seco (menor incidência) compreende os meses de julho a dezembro, observamos que a primeira coleta (novembro 2011) foi realizada na época seca e a segunda (maio 2012) no período chuvoso, apesar de neste mês não ter houve precipitações significativas na região (figura 3). 


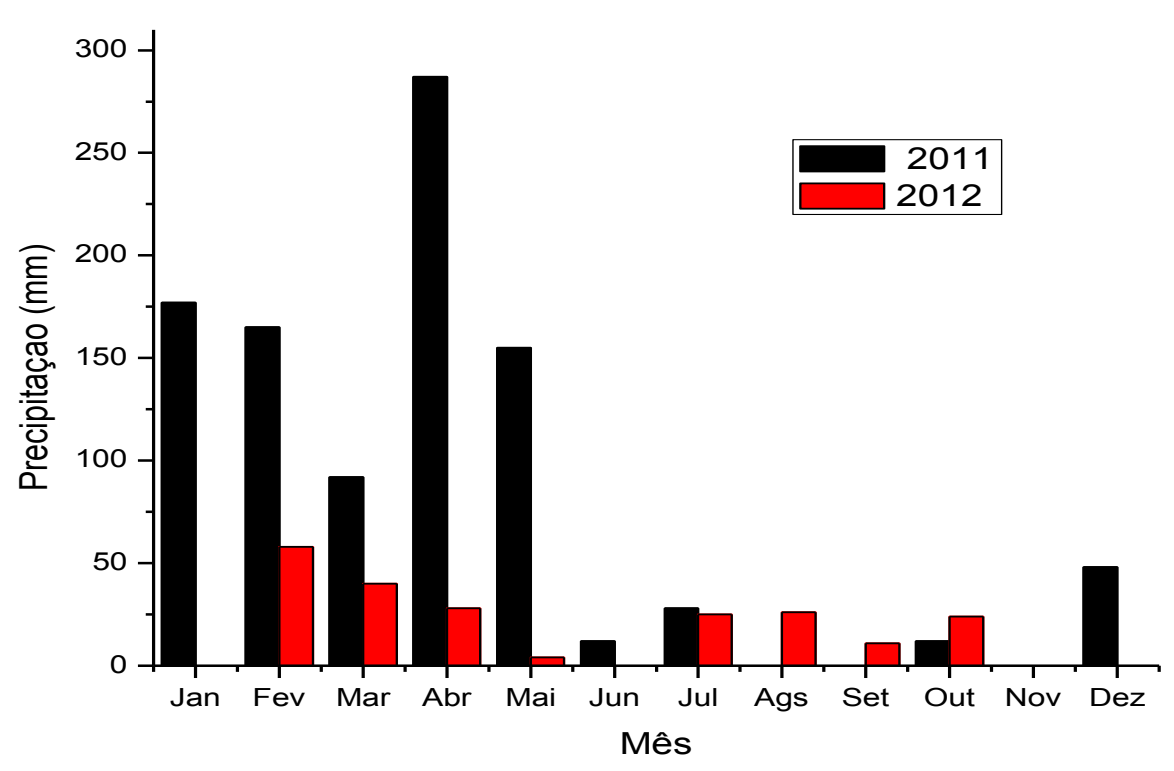

Fonte: INMET (2012).

Figura 3 - Acumulado das precipitações pluviométricas dos anos 2011 e 2012.

Uma questão fundamental no processo de despoluição e/ou de autodepuração de ambientes aquáticos, é a oxidação química das substâncias potencialmente nocivas, em elementos não prejudiciais ao meio e aos seres que dele dependem. Dentre os elementos oxidantes naturais mais importantes tem-se o oxigênio molecular dissolvido $\left(\mathrm{O}_{2}\right)$. Como produtos da oxidação tem-se gás carbônico é água (BAIRD, 2011). De acordo com Baird (2011), o $\mathrm{O}_{2}$ em ambientes aquáticos decorre, principalmente, de processos mecânicos (quedas d'água) e biológicos (fotossíntese), sendo um elemento influenciado pela temperatura e pressão. Ainda segundo este mesmo autor, a quantidade deste elemento em águas naturais é pequena, variando de $14,7 \mathrm{mgO}_{2} / \mathrm{L}$ na temperatura de $0 \stackrel{\circ}{\circ}$ e pressão de 1 atm a $7,0 \mathrm{mgO} / \mathrm{L}$ na temperatura de 35 ㄷ $\mathrm{C}$ e pressão de $1 \mathrm{~atm}$, portanto, deficiente do ponto de vista ecológico.

Os resultados de OD (tabela 2), ficaram compreendidos entre 7,21 a 13,83 mg/l para o período seco e 3,93 a 6,9 mg/l no período chuvoso. Apenas o ponto JU ficou ligeiramente abaixo dos $4 \mathrm{mg} / \mathrm{L}$ estabelecidos pela resolução CONAMA N 357/2005, sendo que este resultado decorre claramente do incremento de matéria orgânica, no rio, carreada pelas águas pluviais da cidade de Upanema. Observa-se um efeito sazonal nos resultados, sendo que no período de maior incidência de chuva ocorre uma diminuição nos valores $\mathrm{OD}$, quando comparado com os de menor incidência pluviométrica. No período seco, os valores de OD firam em média 2,68 vezes acima do limite mínimo do CONAMA, enquanto que no período chuvoso os valores situaram-se, em média, apenas 1,34 vezes. Isto mostra, como era esperado, que no período em que há maior presença de matéria orgânica no meio aquático, menor é as concentrações de $O D$, ou seja, temos uma relação direta entre matéria orgânica e a concentração de OD (SIQUEIRA, 2012; ALVES, 2012). 
Tabela 2 - Valores encontrados do parâmetros DBO, OD, turbidez, ST, pH, T, CF, PT e NT obtidos nos quatro pontos de coleta ao longo do Rio do Carmo durante o período seco e chuvoso do ano de 2011/2012. PERÍODO SECO PERÍODO CHUVOSO

\begin{tabular}{lccccccccc}
\hline PARÂMETRO & $\mathrm{MB}$ & $\mathrm{JU}$ & $\mathrm{AF}$ & $\mathrm{JF}$ & $\mathrm{MB}$ & $\mathrm{JU}$ & $\mathrm{AF}$ & $\mathrm{JF}$ & $\mathrm{LMP}$ \\
\hline $\mathrm{DBO}(\mathrm{mg} / \mathrm{L})$ & 6,22 & 3,73 & 6,22 & $\mathbf{1 2 , 2 5}$ & $\mathbf{1 1 , 0 5}$ & 1,24 & $\mathbf{1 2 , 6}$ & 6,33 & $\leq 10$ \\
\hline OD $(\mathrm{mg} / \mathrm{L})$ & 13,83 & 7,21 & 10,19 & 10,99 & 5,76 & $\mathbf{3 , 9 3}$ & 4,77 & 6,9 & $\geq 4$ \\
\hline Turb. (UNT) & 2,28 & 21,43 & 34,1 & 12,78 & 7,66 & 14,04 & 6,5 & 3,55 & $\leq 100$ \\
\hline $\mathrm{ST}(\mathrm{mg} / \mathrm{L})$ & 47 & 41 & 104 & 159 & 102 & 108 & 126 & 174 & $\leq 500$ \\
\hline $\mathrm{pH}$ & 8,09 & 7,56 & 8,33 & 8,3 & 6,93 & 6,97 & 7,27 & 8,46 & $6,0-9,0$ \\
\hline $\mathrm{T}\left({ }^{\circ} \mathrm{C}\right)$ & 28,9 & 28,6 & 30 & 29,8 & 28,2 & 29 & 28,8 & 29,5 & $\leq 40$ \\
\hline $\mathrm{CF}(\mathrm{NMP} / 100 \mathrm{~mL})$ & $\mathbf{2}$ & $\mathbf{2 1 6 0 0}$ & $\mathbf{3 3}$ & $\mathbf{3 3}$ & $\mathbf{8}$ & $\mathbf{1 3 0}$ & $\mathbf{2 6}$ & $\mathbf{2 1}$ & 3 \\
\hline $\mathrm{PT}(\mathrm{mg} / \mathrm{L})$ & 0,01 & 0,04 & 0,03 & 0,02 & 0,07 & 0,16 & 0,09 & 0,11 & $\leq 0,15$ \\
\hline $\mathrm{NT}(\mathrm{mg} / \mathrm{L})$ & 6,94 & 6,94 & 6,95 & 6,94 & 4,64 & 4,67 & 4,66 & 4,69 & - \\
\hline
\end{tabular}

Todos os resultados de turbidez (tabela 2), firam abaixo do limite máximo permitido ( $\leq$ 100 UNT) proposto pelo CONAMA. A turbidez, pode ser entendia como o grau de atenuação da intensidade que um feixe de luz sofre ao atravessar a água. Esta diminuição do feixe de luz em águas superficiais decorre da presença de componentes orgânicos e inorgânicos como areia, sílte, argila, algas, bactérias, plâncton em geral, bem como de esgotos domésticos e industriais, sendo que a presença destes componentes, em águas superficiais, está associada principalmente ao escoamento de águas pluviais (CETESB, 2008). Um ponto interessante, diz respeito a sazonalidade. Teve-se uma inversão de valores, ou seja, no período chuvoso o valor médio $(7,94)$ da turbidez ficou menor quando comparado ao valor médio $(17,65)$ do período seco. Este resultado está relacionado, principalmente, há algas, plâncton e plantas aquáticas. Este resultado tem relação com os valores mais elevados de nitrogênio total (maior disponibilidade de nutriente no meio aquático) e OD (maior oxigenação do meio aquático pelo fotossíntese) no período seco, que favorecem condições favoráveis para o aumento desses organismos.

Os resultados de sólidos totais tem relação direta com a sazonalidade, uma vez que os valores de ST são maiores no período chuvoso, significando um maior incremento dos teores de sais minerais neste período. Outro ponto importante diz respeito aos valores mais elevados nos pontos AF e JF (nos dois períodos) em relação aos demais e do ponto JF em relação ao ponto AF. Neste dois pontos há uma presença antrópica marcante, como locais para dessedentacão de animais, pesca, caça, lazer (ponto JF) além de serem pontos fortemente influenciados pela região estuaria. Os altos resultados do ponto JF, tem relação direta com as mares e com as industrias salineiras instaladas na região, que por falta de compromisso ou fiscalização, lançam as águas mães com valores mais alto de sais do que permitidos pelas leis vigentes.

Segundo a Companhia Ambiental do Estado de São Paulo, a temperatura é parte do regime climático normal e corpos de água naturais apresentam variações sazonais e diurnas, bem como estratificação vertical. A temperatura superficial é influenciada por fatores tais como latitude, altitude, estação do ano, período do dia, taxa de fluxo e profundidade. A elevação da temperatura em um corpo d'água, geralmente, é provocada por despejos industriais (indústrias canavieiras, por exemplo) e usinas termoelétricas. Os resultados de temperatura como esperado, em função da ausência de fontes térmicas poluidoras, possuem valores que estão dentro da normalidade. Os valores de T giraram em torno de 28 a $30{ }^{\circ} \mathrm{C}$, indicando que as águas do Rio do Carmo não recebem descargas de águas em elevadas temperaturas. Os resultados são 
semelhantes aos encontrados em outros trabalhos realizados na região (MARTINS et al. 2008a, 2008b; MORAIS et al, 2009).

Para rios classe III, a resolução CONAMA no 357/2005 estabelece uma faixa de pH entre 6,0 e 9,0, significando que nos períodos estudados, os resultados estão de acordo com a resolução. A pequena variação no $\mathrm{pH}$ (tabela 2), entretanto, revelou uma ótima capacidade de tamponamento pelo rio, de modo que, os valores determinados do $\mathrm{pH}$ variaram dentro de uma faixa ligeiramente básica, resultado este que pode ser explicado pela geologia da região. No período chuvoso há uma pequena redução dos valores de $\mathrm{pH}(6,93$ - 8,46) devido, principalmente, à decomposição da matéria orgânica carreado pelas águas da chuva, (SIQUEIRA, 2012).

A resolução CONAMA $n^{\circ} 357 / 2005$, diz em seu artigo 4, inciso IV, que as águas doces classe III podem ser destinadas ao abastecimento para consumo humano, após tratamento convencional ou avançado, irrigação de culturas arbóreas, cerealíferas e forrageiras, pesca amadora, recreação de contato secundário e dessedentacao de animais. Entretanto, a mesma resolução só estabelece valores máximos permitidos para coliformes termotolerantes. Não é difícil imaginar que essas águas podem está sendo usadas para consumo humano, direto ou indiretamente, uma vez que existe povoados e comunidades ao longo do rio e que os mesmos, provavelmente, não tem acesso a águas advindas de sistema de tratamento e abastecimento público. Quando o assunto é potabilidade, a portaria no 2.914, de 12 de dezembro de 2011, diz que devemos ter zero de coliformes fecais em $100 \mathrm{ml}$ de água tratada. Sendo assim, podemos dizer que ela está impropria para uso humano, como por exemplo cozinhar e beber. Nos dois períodos estudados os maiores valores de CF foram encontrados no ponto JU, com o decréscimo do valor em direção ao ponto JF. O valor alto de CF no ponto JU, condiz com o esperado, já que quanto maior a proximidade dos centros urbanos maior é a descarga de efluentes, sem tratamento, no curso d'água. Já os valores decrescente no sentido JU-JF está relacionado a dispersão, diluição e oxidação dos micro-organismos responsáveis pelos valores de CF. Resultados semelhantes foram obtidos por Morais et al. (2009) e pelo estado do Rio Grande do Norte (2012) em outros trabalhos realizados em rios da região.

A presença de fósforo em águas naturais está associada principalmente à descarga de esgotos sanitários (matéria orgânica fecal e surfactantes), alguns efluentes industriais, como os de indústrias de fertilizantes, pesticidas, químicos em geral, conservas alimentícias, abatedouros, frigoríficos, laticínios e as águas drenadas de áreas agrícolas e urbanas. O principal problema desencadeado por elevadas concentrações de fósforo em um manancial d'água, está relacionado ao processo de eutrofização, isso porque o fósforo, assim como o nitrogênio, constitui um nutriente limitante para processos biológicos. Os resultados de fósforo total, ficaram no geral, todos abaixo do limite máximo permitido $(\leq 0,15 \mathrm{mg} / \mathrm{L})$ estabelecido pela resolução CONAMA $\mathrm{n}$ $357 / 2005$. A única exceção, como era esperado, o ponto JU foi o que apresentou sempre os maiores resultados, encontrando-se o valor de $0,16 \mathrm{mg} / \mathrm{L}$ no período chuvoso. Este resultado decorre da sua proximidade da cidade de Upanema. Quanto ao efeito sazonal, novamente temos uma elevação da concentração de PT em função do aumento de lixiviação de constituintes orgânicos para o leito do rio. Os fatores encontrados neste ponto, também foram observados por Silva et al. (2009), ou seja, os valores de fósforo total são fortemente influenciados pela sazonalidade e pelas atividades antrópicas.

A resolução do CONAMA, não estabelece valores limites para concentração de NT em águas doces classe III. Ela faz apenas inferência para águas doces classe I e II. No artigo 10, § 3 o diz; quando o nitrogênio for fator limitante para eutrofização, nas condições estabelecidas pelo 
órgão ambiental competente, o valor do nitrogênio total (após oxidação) não deverá ultrapassar 2,18 mg L-1 para ambientes lóticos, na vazão de referência. Para Siqueira (2012), no meio aquático não há um padrão definido de distribuição de nitrogênio, de modo que essa distribuição dependerá de vários fatores, entre eles, o balanço entre as formas nitrogenadas, estratificação térmica e/ou química, densidade de organismos fotossintetizantes, em especial os fitoplanctônicos, volume de chuvas e naturalmente volume de material de origem alóctone, especialmente de origem antrópica. Entre pontos da mesma coleta, não temos uma variação significativa nos valores de NT, de modo que essa concentração, provavelmente, tenha origem da decomposição de matérias orgânicos no fundo do rio ou pode ser de origem geológica. Isso por que, o efeito sazonal não contribuiu para um aumento da concentração de NT, como é esperado, ao invés disso houve apenas a diluição e ou dispersão do nitrogênio total.

\section{Índice de Qualidade da Água}

O IQA é uma fonte de informação importantíssima sobre o estado de qualidade d'água de um manancial. Para o seu cálculo, são usados os parâmetros $\mathrm{OD}, \mathrm{pH}, \mathrm{T}$, Tur, $\mathrm{DBO}_{5}, \mathrm{ST}, \mathrm{NT}$, PT e CF. Uma vez determinado, ele serve de referência no gerenciamento ambiental, meio de divulgação da qualidade da água a sociedade civil e um mecanismo de reunião de parâmetros em uma única variável de fácil divulgação e interpretação. Tem como principal desvantagem, a perda de informações importantes que apenas o parâmetro individual poderia fornecer. Além disso, os efeitos originários de outras fontes de poluentes, não são representados (LOPES, 2007). Neste caso, em um programa de monitoramento as informações individuais de cada parâmetro também são importantes.

A BHRC esta inserida em um contexto no qual deterioração do Rio do Carmo (principal rio da bacia) é eminente. Como discutido anteriormente, atividades agrícolas, cidades e povoados, extração de petróleo, pecuária, extração de sal marinho e piscicultura são importantes fontes antrópicas que podem contribuir para o decréscimo da qualidade da água neste meio aquático. Estas características também foram encontradas por Martins et al $(2008 a, b)$, ao estudar a qualidade da água do Rio Apodi/Mossoró.

Conforme os resultados apresentados na figura 4 observa-se que no geral a qualidade da água do Rio do Carmo, nos pontos monitorados, está boa (exceto no ponto JF, onde na primeira coleta apresentou qualidade regular), apresentando uma diminuição da qualidade quando se examina pontos localizados mais próximos da foz. Esta constatação evidencia que em todos os pontos ocorrem influências externas, que juntas corroboram para o decréscimo da qualidade da água no sentido da barragem para a foz do rio (parte perenizada do rio). Essas atividades antrópicas alteram a qualidade da água de ponto para ponto na direção da foz, de acordo com o que é realizado no local, resultando em índices diferentes em locais diferentes. De maneira geral a qualidade da água vai piorando à medida que segue o curso do rio no sentido nascente -foz, sendo este resultado consequência do incremento de efluentes da cidade de Upanema, comunidades e atividades econômicas por onde o rio passa. Resultados semelhantes foram encontrados por Araújo et al $(2007)$ e Souza et al $(2011,2012)$ em seus estudos sobre a qualidade do Rio Mossoró. Lopes (2007), também observa um decréscimo da qualidade da água do Ribeirão de Carrancas, ao observar que os melhores valores de IQAs são encontrados em pontos a montante de lançamentos de efluentes urbanos e industriais e de áreas agrícolas. 


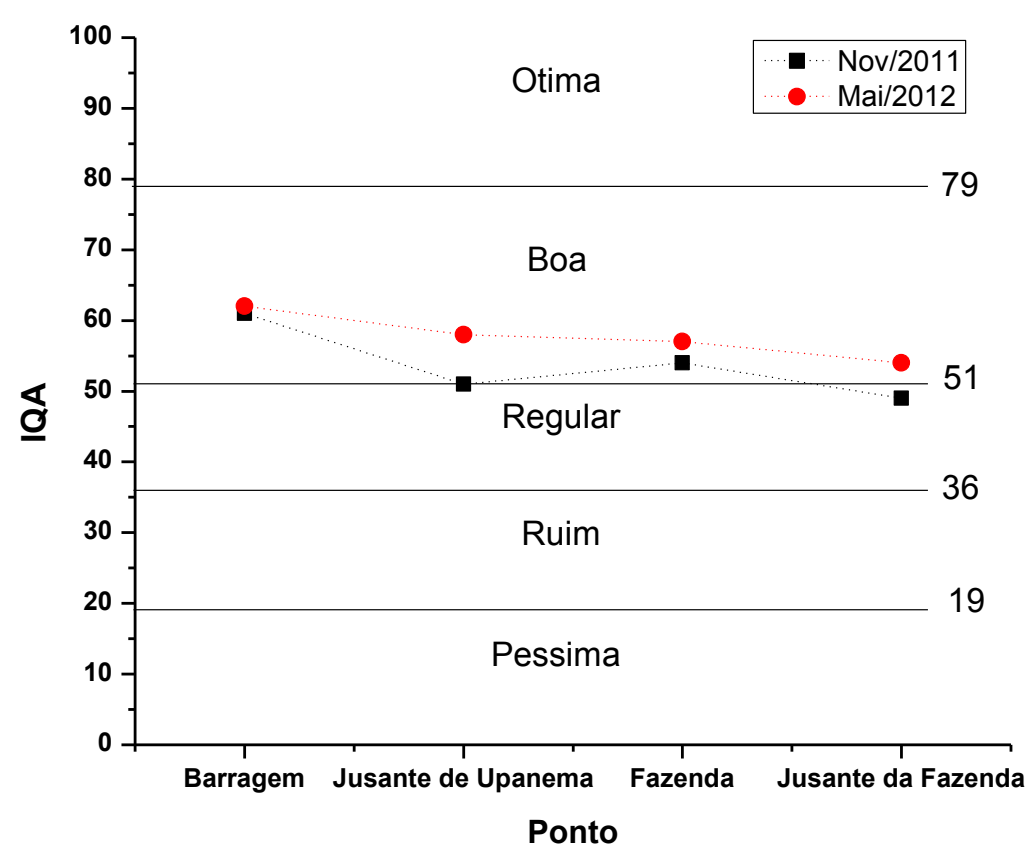

Figura 4 - IQA para os quatro pontos nas duas coletas

\section{Influência da sazonalidade no IQA-NFS.}

Com o início das chuvas tem-se o efeito sazonal de alterar os parâmetros estudados e os índices calculados de acordo com a sua intensidade, quantidade e qualidade do material carreado para o leito do rio. Sabendo que para esta região, o período chuvoso do ano está compreendido entre os meses de janeiro a junho e que o período seco compreende os meses de julho a dezembro, observa-se que a primeira coleta foi realizada na época seca e a segunda no período chuvoso (figura3). Conferindo-se essa figura pode-se observar que o índice pluviométrico do período chuvoso no ano de 2012 foi muito abaixo que o de 2011 que é o considerado normal na região.

Ao contrário de Lopes (2007), que observou menores valores de IQAs no período de maior incidência pluviométrica, observou-se que as chuvas são um forte agente sazonal que acabam melhorando o índice de qualidade da água no período chuvoso, como mostra a comparação dos resultados da primeira coleta (seca) com os resultados da segunda (chuva). Para ele, a menor vazão do rio, associado ao fácil acesso de animais ao curso d'água para dessedentação, acaba proporcionando maior concentração de materiais nas margens do rio. Há nível individual os parâmetros que contribuem para diminuir a qualidade da água são os coliformes fecais nas duas coletas e em todos os pontos. Neste sentido comprovou-se em campo a presença de animais nas margens dos rios, bem como foi encontrado fezes de animais e humanas próximos às margens do rio e restos de comida e materiais como garrafas PET e plásticos que comprovam a presença humana. Outros fatores que apareceram negativamente, foram a DBO na segunda coleta no ponto $\mathrm{MB}$ e $\mathrm{AF}$ e no ponto JF na primeira coleta (valores em negrita na tabela 2), e o oxigênio dissolvido na segunda coleta e ponto JU. A soma de um valor alto para coliformes e DBO no ponto JF fizeram com que o mesmo deixa-se a faixa de água de boa qualidade para ficar na faixa de água de qualidade regular no período seco. Resultados semelhantes foram também 
encontrados por Lopes (2007), ao concluir que altos valores de coliformes e baixas concentrações de oxigênio da água, acabam contribuindo significativamente para redução da qualidade da água.

Bordalo et al. (2001) e Molina (2006), também concluíram que baixos valores de IQAs em estações secas, estão associados ao menor poder de diluição com o lançamento contínuo de poluentes, especialmente esgotos domésticos, a montantes de cursos de rios. Os resultados também refletiram o efeito antrópico das cidades de Upanema e da fazenda de melão, fazendo com que os pontos a jusante desses locais fossem os que apresentassem os menores índices de IQA.

\section{CONCLUSÕES}

Com exceção dos valores de coliformes fecais e alguns valores de DBO e OD, todos os parâmetros físicos e químicos, d'água, estão de acordo com os valores permitidos pela resolução CONAMA no 357/2005. Isso indica que apesar de termos presença marcante de fontes antrópicas, a qualidade da água ainda encontra-se boa em relação a estes parâmetros estudados. Entretanto, nos pontos em torno da cidade de Upanema e da fazenda de melão, percebe-se um aumento nos resultados dos parâmetros, quando comparados com os demais, sendo está questão mais visível nos valores de CF, DBO e PT. Pode-se dizer esses valores são consequência da descarga de efluentes urbanos (sem tratamento), combinados com a lixiviação de constituintes para o curso do rio, pelas água das chuvas, advindos das atividades agropastoris desenvolvidas com as águas do rio. Isso torna claro a necessidade de atividades de conscientização, fiscalização e implementação de programas de monitoramento, uma vez que este rio é um importante manancial superficial d'água para região.

Os resultados do IQA, comprovam o que os parâmetros individuais mostraram. O IQA calculado situou a qualidade da água dos pontos estudados, entre regular e boa. Além disso, Os resultados obtidos são fortemente influenciados pelas atividades antropogênicas locais (espacialidade) e pela chegada das chuvas (sazonalidade), sendo que no período chuvoso temos uma melhora na qualidade da água.

No geral, apesar de termos, ainda, uma água "boa" no Rio do Carmo, já é forte a presença do decréscimo da qualidade de suas águas, sendo este decréscimo crescente no sentido da foz do rio.

\section{REFERÊNCIAS BIBLIOGRÁFICAS}

1. ALVES, I. C.; EL-ROBRINI, M.; SANTOS, M. L. S.; MONTEIRO, S. M.; BARBOSA, L. P. F.; GUIMARÕES, J. T. F.. Qualidade das águas superficiais e avaliação do estado trófico do Rio Arari (Ilha de Marajó, norte do Brasil). Acta Amaz. 2012, vol.42, n.1, pp. 115-124. ISSN 0044-5967.

2. ARAÚJO, V.S; SANTOS, J. P.; ARAÚJO, A. L. C. Monitoramento das águas do Rio Mossoró/RN, no período de abril/2005 a julho/2006. Holus. A. 3, maio de 2007.

3. BORDALO, A. A.; NILSUMRANCHIT, W.; CHALERMWAT, K. Water quality and uses of bang pakong river (Estern Thailand). Water Research, v.35, n.15, p.3635 - 3642, 2001.

4. BRASIL. Ministério da Saúde. Secretaria de Vigilânica em Saúde. Coordenação-Geral de Vigilância em Saúde Ambiental. Portaria MS n. 518, de 25 de março de 2004. Série E: legislação de saúde. Brasília: editora MS, 2005. 
5. Ministério do Meio Ambiente. Conselho Nacional do Meio Ambiente. Resolução no. 357, de 2005. CONAMA: resoluções e outros atos. Brasília, DF, 17 mar. 2005. Disponível em: < http://www.mma.gov.br/port/conama/legiabre.cfm?codlegi=459 > Acesso em: 15 set. 2011.

6. CHAPMAN, D.; KIMSTACH, V. Chapter 3: selection of water quality variables. In: UNESCO/WHO/UNEP. Water Quality Assessments: a Guide to Use of Biota, Sediments and Water in Environmental Monitoring. 2. ed. London EC4) 4EE: WHO by F \& FN Spon, 1996. 651 p.

7. DERISIO, J. C.. Introdução ao Controle de Poluição Ambiental. 2. ed. São Paulo: Signus, 2007. 192 p.

8. FERREIRA, L. M.; IDE, C. N.. Avaliação comparativa da sensibilidade do IQA-NSF, IQA-Smith e IQAHorton, aplicados ao Rio Miranda, MS. In: CONGRESSO BRASILEIRO DE ENGENHARIA SANITÁRIA E AMBIENTAL,21.,2001, João Pessoa. Anais... João Pessoa: ABES, 2001. Disponível em:< http://www.bvsde.paho.org/bvsaidis/saneab/brasil/iv-019.pdf>. Acesso em: 16 jun.2012.

9. LOPES, F. W. A. Avaliação da qualidade das águas e condições de balneabilidade na bacia do Ribeirão de Carrancas - MG 2007. 96 f. Dissertação (Mestrado em Engenharia Florestal) Universidade Federal de Lavras, Minas gerais, 2007.

10. LOPES, F. W. A.. Avaliação da qualidade das águas e condições de balneabilidade na bacia do Ribeirão de Carrancas-MG. 2007. 96 f. Dissertação (Mestrado em Engenharia Florestal) Universidade Federal de Lavras, Lavras, 2007.

11. MARTINS, D. F. F.; SOUZA, L. D.; CASTRO, S. S. L.. Qualidade físico-química das águas da bacia do rio Apodi Mossoró: II- variabilidade temporal. Revista Química no Brasil, v. 2, p. 45-56, 2008b.

12. MARTINS, D. F. F.; SOUZA, R. B.; OLIVEIRA, T. M. B. F.; SOUZA, L. D.; CASTRO, S. S. L.. Qualidade físico-química das águas da bacia do Rio Apodi /Mossoró:I - Variabilidade espacial. Revista Química no Brasil, Campinas, v. 2, n. 1, p. 61-74, 2008a.

13. MERTEN, G. H.; MINELLA, J.P.. Qualidade da água em bacias hidrográficas rurais: um desafio atual para a sobrevivência futura. Agroecologia e Desenvolvimento Rural Sustentável, Porto Alegre, v.3, n.4, 2002.

14. MILLER, G. T. Ciência Ambiental. São Paulo: Cengage Learning, 2008.

15. MOLINA, P. M. Diagnóstico da qualidade e disponibilidade de água na micro-bacia do Córrego Água da Bomba 2006. 158 f. Dissertação (Mestrado em Engenharia Civil) - Universidade Estadual Paulista, Ilha Solteira, 2006.

16. MORAIS, P. R. F; OLIVEIRA, T. M. B. F; SOUZA, L. D; CASTRO, S. S. L.. Determinação do IQA nas águas da bacia hidrográfica Apodi/Mossoró em regiões de baixa e alta influência da zona urbana. In: 3ㅇ Congresso Norte Nordeste de Química, 2009, São Luiz-MA. Anais do III CNNQ, 2009.

17. OLIVEIRA, J. P.. Dinâmica Sócio-espacial e degradação ambiental na Sub-Bacia do Rio do Carmo. 2001. 150f. Dissertação (Mestrado em Desenvolvimento e Meio Ambiente) - Programa Regional de Pós-Graduação em Desenvolvimento e Meio Ambiente, Universidade do Estado do Rio Grande do Norte, Mossoró, 2001.

18. PEREIRA, L. A. M; RODRIGUES, M. A. R.. Estudo sobre a aplicabilidade do índice do estudo trófico de Carlson (1977) na região Lisboa e Vale do Tejo. Centro de Documentação e Informação / CCDR-LVT. Lisboa, dez 2006. 
19. PERNAMBuCO. Agência Estadual de Meio Ambiente. Seleção de índices e indicadores de qualidade da água: aplicação dos índices selecionados. Pernambuco, 2006.

20. RIO GRANDE DO NORTE. Rede compartilhada de monitoramento da qualidade da água. Programa Água Azul: 1 relatório trimestral. Natal, 2009.

21. RIO GRANDE DO NORTE. Secretaria de Estado dos Recursos Hídricos (SERHID). Projeto PROÁGUA/SEMI-ÁRIDO. Plano de recuperação ambiental do trecho inferior do Rio do Carmo. Relatório Final: tomo I, II e III. Natal, 2005.

22. RIO GRANDE DO NORTE. Secretaria Estadual de Meio Ambiente e Recursos Hídricos (SEMARH). Ficha técnica do reservatório Umarí. Natal, 2012.

23. SÃO PAULO. Companhia Ambiental do Estado de São Paulo. Relatório de qualidade das águas superficiais do estado de São Paulo: apêndice B - índices de qualidade das águas. São Paulo, 2008. (Série Relatórios).

24. SILVA, L. M.; SOUZA, L. D.; MORAIS, L. A.; DANTAS, T. C. M.; SILVA, A. G.; CASTRO, S. S. L.. Influencia natural e antrópica nos níveis de poluição por fósforo na bacia hidrográfica do rio Apodi/Mossoró. In: congresso da SBQ-2009, Fortaleza. Anais da SBQ - 2009, v. 1.

25. SIQUeIRA, G. W.; APRILE, F.; MIGUEIS, A. M.. Diagnóstico da qualidade da água do rio Parauapebas (Pará - Brasil). Acta Amaz. [online]. 2012, vol.42, n.3, pp. 413-422. ISSN 0044-5967.

26. SOUZA, L. D.; MORAIS, L. M. S.; CASTRO, S. S. L.. Monitoramento espaço temporal da qualidade das águas da bacia hidrográfica do rio Apodi/Mossoró RN. Química no Brasil, v. 4, p. 70-80, 2010.

27. SOUZA, L. D; MARTINS, D. F. F; SILVA, K.M.B; LOIOLA, M. I. B.; MEDEIROS, J. F. Temporal and physiological influence of the absorption of nutrients and toxic. Journal of Environmental Monitoring (Print) , v. 1, p. 10.1039/c0em003, 2011.

28. SOUZA, L.D.; CASTRO, S. S. L., MARTINS, D. F. F. Qualidade físico-química das águas da bacia do rio Apodi/Mossoró: II variabilidade temporal. Química no Brasil. , v.2, p.45 - 56, 2008.

29. SOUZA, L.D.; CASTRO, S. S. L., MARTINS, D. F. F.; OLIVEIRA, T. M. B. F.; BATISTA, R.S.. Qualidade físico-química das águas da bacia do Rio Apodi/Mossoró. Química no Brasil, v.2, p.61 - 74, 2007.

30. SOUZA, L.D.; CASTRO, S. S. L.; DANTAS, I. M.; SILVA, G. H. G. ; CASTRO, R. S.. Sustainable use of water in tropics amd subtropics: the case of Apodi/Mossoró river basin in the Brasilian semi-arid. In: Carolina Bilibio; Oliver Hensel; Jeferson Francisco Selbach. (Org.). Sustainable Water Management in the Tropics and Subtropics - and Case studies in Brasil. jaguarão: Fundação universidade Federal do Pampa,2012,v.3. 